\title{
School v. Schools: Is Italy Shying Away From Italy? Understanding Government and Institutional Practices in Italy From Within an Educational Framework
}

\author{
Raffaella Cantillo ${ }^{1}$ \\ ${ }^{1}$ Istituto Comprensivo Statale 'I C Picentia', Pontecagnano, Salerno, Italy \\ Correspondence: Raffaella Cantillo PhD, Istituto Comprensivo Statale 'I C Picentia', Pontecagnano, Salerno, \\ Italy.
}

Received: November 9, 2019

Accepted: December 8, 2019

Online Published: December 22, 2019

doi:10.20849/jed.v3i3.668

URL: https://doi.org/10.20849/jed.v3i3.668

\begin{abstract}
This article analyses the Italian school system vis-à-vis other European systems from an objective perspective; the paper seeks to do this by elucidating some of its opaque aspects. It engages with an idea of cultural identity and what can be identified as the most obvious threats posed to it; Italy's Gestalt at present is coterminous with that of the extant European educational framework, which formerly Italians themselves worked hard to bring about. Hence, raising awareness as to the modality that our country's laws and agreements impact all aspects of our society becomes a main educational concern in this field of study.
\end{abstract}

Keywords: schools, Europe, Gestalt, identity, culture, government, inclusion

\section{Introduction}

This article begins by identifying questions about the Italian school system. Some of these will sound rhetorical, some old-fashioned or 'self-referential' as they focus on our school system by addressing its identity and its practices. The popular feel that it is an 'old system' reflects on it becoming overly self-referential in its modalities too, while scholarly research focused on comparisons between schools abroad and other educational systems seem sparser by the day and mainly found online, in blogs, chats on social media or online interviews and articles. 'What is Italian school today? What is its Status? What or who are Italian teachers today? Is Italy and its schooling system shying away from itself? Is it really trying to copy, take the guise of, other educational systems? Are Italy and Italians rescinding umbilical cords with its government's policies, with Europe and with our institutional ties? Within the schools' context, such concerns elicited several discussions - voiced by the media and more generally at board and school meetings among colleagues and peers. In the classroom, our teenage students are, I am enthusiastic to say, most eager to listen to and find out about what it means to be law-abiding Italian citizens. As we are also European they are also very keen to learn about what being European means, in Italian schools and abroad.

With this in mind, the paper aims to provide an excursus of the foremost differences between Italian schools and other European and non-European educational systems. This is a challenging, complex task, which involves taking cognizance of the tensions within and without the political sphere, nationwide and internationally. Particularly, I will mention some of the most prominent differences between the Italian and the British educational system, as these are the two educational systems where I was able to carry out my research - and I can confidently say to have worked in and accrued much experience from both schooling systems. Prior to this, however, I will briefly consider the concept of what is thought of as old and new within educational systems; ideas of old and new are often found as being hand-in-hand with parallel ideas of stranger, foreign, familiar, alien or well-known. It is safe to say that, for instance, something is considered 'old' when its characteristics or practices are perhaps too well-known and when such practices have been known or used within a system for too long; by contrast, something new often represents the fruit of discovery or invention, therefore previously unknown or considered 'out of bounds with' and beyond our experiential confines.

In this connection, with regard to the Italian school systems, many among colleagues, students' parents and friends often complain that 'our system is old' - but is this true? How old is old enough for a change to occur? Should a change occur to our system? If so, what sort of change? An embryonic metaphor - or is it a Freudian one - might serve here perhaps when looking at some of the problems Italy, our republic and democracy, is 
facing today. Some reviews from abroad have also considered evaluating our system - sometimes bordering on being offensive, as some of the humiliating remarks found online are, frankly, disheartening and also - may I suggest - horribly untrue: Consider this for example:

"The [Italian] school system has had a good reputation in the past, but it is now very old fashioned. It tends to focus a lot on rote memorization and obedience over thinking out of the box" [from 'educazioneglobale.com']

Not wishing to lack in respect for those who wrote on this misinformed blog, nor to understate the importance of freedom of speech and free divulging of one's ideas, one should remember that Italy has one of the most ancient and well-read, educated cultures of all times. 'Rote memorization' has not been done in Italy for many years now, and 'obedience' normally just means behaving in respect of the school rules - the general idea being that, in order to function normally within society, one has to abide by certain formal codes. Respect for the rules means keeping everyone safe, and once a child understands this they usually behave and are well-mannered. 'Thinking out of the box' is also greatly encouraged, 'doing things differently' if it helps in understanding and learning is much sought for in our schools as rather than stifling a child's problem solving skills, it promotes their ability to overcome complexity and helps develop their creativity in all its forms. Furthermore, the above-mentioned review of Italian schools seems to purport that 'when you get a good teacher' it all works out somehow - thus implying a rather worrying and unconvincing suspicion raised around MIUR's school-teacher professionals; as unfortunately such narrow-minded remarks influence the wider public arena, this attitude sadly deeply undermines our profession as it tries to suggest that there is an inherent flaw corrupting a teacher's ability to carry out their job proficiently. If you have to be a miraculous exception in order to be considered a 'good teacher', it logically follows that the rest are bad teachers. Odd is it not, that in order to be considered acceptable one has to become the exception to the rule. Is this true of teachers in Italian schools? I think not. This was just one example of a bad type of stereotypical assumption about foreign teaching systems. (Note 1)

This notwithstanding, there are good reviews, some of which are rather more informative and considerate; these typically outline the good as well as the bad aspects of our (or any other) educational system. (Note 2) What is particularly worrying however - and I am glad that I have the opportunity to voice my concern here - is that, most times, such skepticism about our educational system comes from Italian colleagues living abroad who rarely fail to present our schools in such a disparaging and stereotypical manner.

While not denying the shortcomings and the general feeling of disaffection which pervades school life, one has to recognize that the Italian school system has its own validity if only insofar as notwithstanding being constantly let down by our government and looked down on by most others, it still manages to get our precious new generations through their mandatory schooling years. MIUR often lacks funds to provide our schools with suitable resources - or occasionally such funds are diverted to less relevant projects; thus in order to improve our performance by allowing schools to acquire newer and safer technologies, new training sessions, new furniture, and render schools generally more secure, within a more conducive, serene and peaceful environment for our student's education to thrive in, we have to start thinking in terms of convincing our government that schools are indeed worth investing in.

\section{Theoretical Background/Methods}

Italy's debt to other, mostly European countries, no doubt, is one of the reasons, together with the need for the government to compensate our country's expenses overseas, to have wrongly led our leaders to cut down drastically on education expenses and at the same time to implement a policy which would foster private education as an alternative schooling system; this 'new system' envisaged by our government in the 90s and early 2000s however, could not, because of the costs involved, ensure that the obligatory education (age 5-16) of less wealthy students would be accommodated. This seemingly accounts for the all-important sociological and ethical complexity we call 'our school system' and its ever-more precarious predicament; when one considers that according to our laws, a school system which denies underage students entry to free state schools is in fact running counter to our Constitution.

The government, teachers and parents in Italy are obliged to make sure that the school environment is safe - this adds to the already overwhelming range of responsibilities we take upon ourselves in our day and age - I doubt very much that teachers' pay-rate in Italy (1500 Euros per month, whether permanent or not) is enough to account for this, regardless of the level of specialism or degree of professional development involved. Hence, the feeling of disaffection and displacement vis-à-vis a system which promises to help our professional category by saying we are instrumental to its development but which is sadly often unable to do so and to face up to new developing challenges such as those posed by social concerns affecting schools presently. Perhaps, Italy today is being forced to battle with an idea of Gestalt, of a superimposed European framework, which however formerly we ourselves sought to bring about. (Note 3) This, coupled with our awareness of how law impacts all aspects of 
our society, the struggle between Italians as a people and Italians as European people has impacted educational fields of study remarkably.

Let's begin by saying therefore, that the Italian educational system is to be seen as part of a much wider global network of educational governmental institutions, both private and government-run, within the European framework, sometimes co-working with non-European institutions worldwide, as was recently pointed out in an outline of the Structure of the European educational systems (2018-19) as well as by an illustration of the Italian Department of Education itself (MIUR). (Note 4) Their presentation provides a range of tables and diagrams to illustrate the many differences and similarities existing among these various countries' schooling systems including the amount of time spent by students on each obligatory step of their school path (p. 20) as well as illustrating the timeframe for students who continue their instruction past the mandatory years (e.g. University or College). (Note 5)

Therefore, it is no mystery that at present it would seem impossible, if not extremely far-fetched, to conceive of the Italian educational system as somehow operating from outside European boundaries. However, the many tensions encompassing our country's political, economic and cultural context must allow for a leap across this very stringent encapsulation of Italy within a European-led ideological grounding - not least, because of the manifold implications of the so-called 'new' technologies and their instantaneous modality of address. Often overstepping cultural, social and well-established language boundaries and codes of behavior, the act of communication itself as several language registers merge as more and more multi-language and multi-cultural people cross paths. We have begun to reason in terms of a plurality of address modalities, something which has no doubt created a gap with previous generations; elderly people these days feel as though they were left behind a long time ago.

Our digital native students, by contrast, have developed their own way of communicating by availing themselves relentlessly of technological devices, no longer considered as new by many, and overstepping what most of us the youth of yesteryear - still feel like important aspects of our society such as the use of titles, saying 'please' and 'thank you'. The media and digital realms have been impacting our languages, ways of life, belief systems and choices for much longer than it may seem - even before awareness was raised about these concerns because of the potential dangers these immensely useful technologies presented - and in fact still do - in the face of the many actions experts have taken to protect the general populace against threats such as hacking, manipulation, viral videos, fake charities, spam, online bullying and terrorism or crime, to mention but a few.

Italy's literary and social past however, until quite recently and well into the 2000 s - does not inform us as readers of such dangers in the way that great personalities such as Orwell or Orson Welles did in their time. Until a few years ago, crime was still seen as something which could only happen outside, in the street, and only of late have people begun to consider surveillance with cameras and to shield their bank accounts from fraud, using strong passwords and adding safeguarding tools to their devices and software. This important aspect meant also having to rethink and deal with a new concept of the idea of privacy which could now be breached even within the confines of one's home. One begins to think of old and new, inside and outside from a different perspective; the shocked realization that unlawful breaches can happen anywhere including schools has such a discouraging effect on our eagerness to promote the safe use of technology that we tend to want to stop students from using their devices. This in turn leads to closure and lack of communication, perhaps the most dangerous aspect of our predicament as teachers within a contemporary e-tech oriented classroom environment. The sole answer in this regard is that in order for students not to be considered as rule-breakers and offenders, they should be placed in a condition which would allow safe use of technology within schools, leaving threats and other dangerous elements out by screening them out through up-to-date filtering devices.

\section{Findings and Discussions}

Thinking primarily about devices and their safe use, the immediate reflection is that nowadays schools and educational practices faced with this worrying complexity worldwide have had to change; devices are now part of the school day and of students' lives and in fact they replace - all too often - their ability to talk to each other, to engage in real conversations and relationships (e.g. parents, friends, boyfriend or girlfriend) rather than virtual ones. This, a teacher will often find, is not due to children being impaired or unable to communicate. It is because they do it in a different and differently effective way. The word 'family' itself has taken on non-traditional connotations, and is often associated with ideas of family breakdown and social criticism. What young students find today is that they can access social networks and establish a range of apparent friendships which seem less psychologically problematic because of their virtual character. However, they can also and often do pose inevitable risks involving their families and their having to take responsibility for what their children write or do online. Supervision and policing should always make sure that underage children are not lured into abuse or illegal or criminal activities - and there are laws which focus on the relevance of international 
awareness as these children will keep on using their devices away from home as well as in other countries they visit. This notwithstanding one has to admit that while awareness of these risks must be kept in focus, there are good aspects to a careful use of social networks.

Today, children and young adults are constantly in touch with friends and family - they can send out a distress signal by instant messaging or chatting - thus reducing the cost of communicating both nationally and internationally. They read and learn much faster than in the past and are able to comment on most aspects of society through posts and feedback 'threads' in their chosen virtual community. They exchange ideas and generally interact socially rather than becoming withdrawn from social life, be this at home, in front of the TV, as some of us did in the ' $80 \mathrm{~s}$ and ' $90 \mathrm{~s}$ when we were their age - and as often happened before for those who were shunned at school and not made welcome in same age environments.

Differently however, from communication modalities used in the last century, we can now reach out past the immediate confines of our homes and conversely, ask for help, give advice, even promote a freelance business and work from home. It is a lot safer in many ways. There is less of a risk of people being made redundant because of the way they look (discrimination) or because of their ways with colleagues (etiquette, professional boundaries). These of course still exist online as for example webinars and online conferencing (e.g. workshops, editing boards, online teach-training or safeguarding courses) require participants to adhere to regulations and moderation standards. Schools therefore represent a threshold scenario where 'human' interaction is associated with virtual environments. The laws that bind such interactions in schools in Italy for example, are clearly spelt out by Italian Law and its Codes (Civil, Penal, Administrative) and of course by the overarching Italian Constitution and code of conduct (both teachers and students/family must respect these).

No doubt, online and virtual environs, including hardware and software used or added to devices in schools, on the other hand rely heavily on international laws and related license agreements. To protect ourselves and our students therefore, we as teachers should be made aware as part of our training of the importance of being able to verify the validity of products and terms and conditions of use which may hold any adult supervising students at work responsible for what happens as they write their responses online (e.g. INVALSI exams, listening and reading comprehension tests, learning platforms and so on). For teachers of EFL such as myself this has become a prominent aspect of my professional development as I constantly try to keep up to date with new laws and deliberations concerning the use of devices in the classroom, to add language software to a whiteboard system or just to extract listening test samples from an online source from my smartphone which will be connected to loudspeakers.

Content, of course, becomes foremost when dealing with teenagers (secondary or junior school) as well as the range of content filters which should be made available and ready on your classroom desktop (where there is one), and able to screen students from using social networks and blocking external contacts from the school's Wi-Fi or routers. In this connection, I shall make a reference to an article by Dron and Anderson on "Issues and Challenges of Educational Uses of Social Networks" which finely outlines the dangers recorded earlier affecting behavior patterns which 'evolved in a different evolutionary landscape'. I am particularly drawn by how 'context switching' is presented in Dron and Anderson's book, Teaching Crowds. (Note 6)

Sanctioning and general disciplinary issues as related to both teachers and students (as being cautious is often not good enough, or legally sufficient) provoke a need to resort to some form of disciplinary action. These include underage confinement orders and escalation in the event of defiance of general warnings for bad behavior consequences, and penalties for the misuse of integrated social network devices and smart-apps or phones in the classroom. I will consider the different modalities and approaches of some of the most common concerns such as how to forewarn students effectively and whether reaching out to their families would be beneficial in case some of their behavior was to be connected with their out of school hours (home or friends). When there are violent or extremely disruptive teenagers, similar considerations are common to very different countries and educational systems. The framework which I would employ is that of 'substance abuse in the family' - 'personal or domestic abuse' - 'peer abuse' or 'non-peer abuse' from which a range of traumatic events might lead students to become psychotic or even to abuse their peers when the memory of past abuses is recalled. Is it possible to make students aware of what is happening to them by showing them that they are reacting to something - rather than intentionally, willingly deciding to offend or harm - and that people they attack often have no knowledge of their past and the memories that may trigger such responses. In the British system for instance, schools offer a continuing counselling service, which goes on to each school level, hand-in-hand with the students' progress (or lack thereof) up to and including at college or university level. The British system allows a child to be imprisoned from as early as age ten, but even if confined as a youth offender, the child has every right upheld as most other children to make it to adulthood and even, eventually, after reintegration, to having a career. Most UK students have already gone through the 'process of justice' of having to respond in court and having a fair 
trial, by the age of fourteen or younger. In Italy, a child would normally only be sent to youth offenders' schools or jails if the crime they committed was deemed to be so grave as to pose a risk to life for others or to their family. Once a youth is convicted and sent to youth or juvenile offenders' jail in Italy, their path is considered near irremediable and their chance to a 'normal' education path or career path is minuscule if compared with that of children in the UK. The document I quote in the endnote provides a useful excursus of this process throughout several different country law systems. (Note 7)

a. Whilst recently in Italy some schools offer parents with difficult children consultations with the school's appointed psychologist or social services staff if they adhere to a counselling project (usually funded by MIUR or other affiliated entities), people are still reluctant to ask for help and there is a feeling of suspicion growing between parents and schools whenever the counselling option comes in the picture. Students' problematic behavior is not generally reported across educational stages as each level is considered as reflecting a specific aspect of a student's growth and with each new level the previous misbehavior is supposed to have been overcome. We don't see it as something which the students will have to carry on their shoulders and feel guilty about throughout their educational path, provided they behave appropriately with each new school year.

Their background is always considered as 'social provenance' and school-related crime always cross paths where dropping out of schools means becoming 'illegal' children and joining street gangs and commit crime, Italian schools set themselves against various organized crime groups and their threats to children and families by trying to keep children in school throughout their mandatory years - and only fail them where it is absolutely necessary; this briefly put, provides an outline of Italian education counter-crime policy which through its manifold projects appeals to all relevant institutions who counter the so-called 'social crimes' from terrorism to criminal association - the fight against substance abuse and social inclusion in schools at all levels being one of the foremost aspects of our institutional mandate. (Note 8)

For this reason and many more, it has become clear that schools in Italy today must liaise with a much wider network of institutions and associations who are willing to provide incentives and feedback to help with tackling the future of our students so that it will not be perceived as a problem but as something to look out to and hope for as they will have matured into society as more aware, law abiding adults, capable of helping others just as they were helped themselves. In this connection, a good example, although in blog format, of the differences and/or similarities between a European and, prospectively in the wake of Brexit, a non-European education system: this blog analyses Italian school rules as opposed to British school rules. (Note 9)

Having taught on supply assignments in the UK for two years and as a permanent school teacher of EFL in Italy (I am Italian) I believe I can say quite objectively that my observations reflect those listed in the blog. However, there are far more relevant questions about differing education systems than just which rules can or can't apply in either context. For example, I found that in the UK mainstream academy schools have their own policy and regulations which may differ quite relevantly from other schools. To add to what can be found in the blog, some schools in the UK - while still mainstream and government run - allow for instance for more inclusiveness than others and vice versa, others seem to provide very little support for both teachers and/or students with special conditions, sometimes lacking Teaching Assistants, quiet rooms or Special Educational Needs professionals. In terms of policing and security for example, there is no question that UK schools are more aware of possible safety concerns coming either from inside or outside the school grounds. Quite relevantly, they differ hugely architecturally as well, and in terms of their location - some are located in the countryside, well out of a town or city's confines, whereas other schools are located within a district area in town or in small villages and hamlets nearby. Some schools will have been built several decades ago, and still be hosted within old buildings often in need of maintenance. Others are rather more modern or even brand-new, and some provide a stark contrast to the typical school environs either because they occupy a much larger area or because they provide for more students and varying ages. All however, whether they are special, mainstream or academies will have the following: catering, music and art dedicated rooms, school libraries, science labs and sports fields, all of which are missing in Italian schools, which takes us shortly back to the 'bad review' section at the beginning of this article, "Infrastructure is really bad: many school buildings would need restoration and sports facilities are often very limited [...] While the schooling is free, books must be purchased at the secondary level". (Note 10)

In British schools, there is always someone at the reception to speak to, and there is an additional safeguarding, counselling and first aid team on site to help teachers and students in case of emergencies. Teachers in the UK are in fact instructed on how to raise attention by sounding an alarm or calling out for help, sometimes even provided by police-style 'walkie-talkies' - while whistleblowing and report procedures are safely and gladly understood by all professionals operating in schools. (Note 11)

b. Notwithstanding the many differing conditions of our schools, the Italian system allows us to provide students with the same effective safe environment you would find abroad. I was personally trained for fire-rescue 
and first aid as early as 2010. There are a range of possible emergency scenarios which are more likely to present themselves in Italian schools: rather small injuries than fire for example, because most schools in Italy are required to be built in steel reinforced cement and there are no curtains or wooden floors - or very rarely i.e. drama classes or small auditoriums; most cabinets are metal or wooden and are (or should be) fixed to the wall. Those very instances where I found myself raising attention for a possible fire starting were always related to something which was happening outside the school grounds, in the fields or woods and so on. Further to this, it is of relevance I believe, to mention that there are normally no Chemistry or Science laboratories in lower secondary schools, whereas we do have labs in high schools, and that there are no special schools in Italy as all our state schools are inclusive by law. One should also perhaps point out that in primary schools - formerly known as elementary schools - children are still required to wear a school apron: not really a uniform, but useful to prevent clothes from becoming irremediably worn out. All other school sectors however, have for a long time now discontinued the use of uniforms - in Italian, 'la divisa' - as these were associated with Fascist schools during Mussolini's dictatorship, making it look as though Italian schools were nostalgic of that dreadful historical era. Some private schools however still enforce it but state schools certainly do not. It is unlawful in our country to show nostalgia or to formulate apologetic remarks about Fascism - this indeed being among few reasons for which a disciplinary sanction would be considered as applicable to teachers. (Note 12) Most subjects are taught in the classroom, even Science, as children are supervised by teachers and may even perform small experiments on foliage or foodstuffs while sitting at their desks. The same can be said about design and technology and art classes - although some schools will have a dedicated room and all schools are now required to have an IT room. Music is taught in class just as Science. Teachers switch from classroom to classroom while children stay in their classroom apart from Physical Education when this is not a theory PE class throughout the day, while in the UK it is often the reverse. There are also no (or if so, they are very rare) specific illustrations of a school's make-up or of its courses on most schools' webpages in Italy, again in contrast with most school webpages abroad (course presentation, time-table, school's profile and outline, policy and school orientation e.g. arts and crafts, sports). (Note 13) To comment on Federica's opinion as expressed in her informative article, I must say I did not notice the 'playfulness' she refers to when considering the British approach to teaching - in fact, my personal impression was to the obverse. Teachers who like a good joke are often 'shunned' by students in the UK - and laughing or joking is certainly not encouraged.

It is interesting however, that she felt this way about the UK educational system, though it seems to me what playfulness there is, is limited to the rhetoric of address in some classes, where hyperbolic remarks are employed to stimulate interest in certain areas of study; this often happens in Drama as well as English classes (e.g. Shakespeare) where explorations of some aspects of British culture or ancient costumes and ways of life are dramatized or even performed through an emphatic highlighting of tone and/or attitude of the teacher/joker. It is a guise, or role however, which does not intend in any way to subtract to the importance or seriousness of teaching Drama or English literature classes. In this connection, I would suggest reading the below example of an 'hyperbole lesson' to clarify this specific point and how to use 'exaggeration' to raise interest in the audience. (Note 14)

c. As a teacher of EFL in lower secondary schools, I am often left to my own devices when it comes to presenting audio-video classes or indeed when preparing my students for INVALSI for English exam - they do not study literary classics in middle school foreign language classes - and there are no language labs to speak of in the schools I have been teaching at here in the South of Italy so far. Nor can I point my student to a nice 'foreign language' section of the school library as there are no school libraries worthy of mention in middle schools and where there is one, this is often simply hosting ancient workbooks and, if you're lucky, a dictionary, usually dating from the '70s. No canteen to speak of, food and drink dispensers are a luxury and are often out of order. Whiteboards don't always work or have the correct software installed and more often than not I had to resort to bringing my own laptop and speakers to allow children to listen to dialogs and prepare for their reading comprehension and listening tests. I often have to provide more material for them to work on such as additional textbooks which I draw tests from and give out to them in photocopy format. I also have to buy my own felt-pens and reams of printing paper. All our colleagues are constantly complaining about how paper and other stationery should be provided by the schools and when the toner goes out we normally have to wait until the week after in order to be able to print materials. Some classrooms still have ancient chalkboards which are obviously causing huge distress as many children (and teachers like myself) are allergic to chalk. This said, we do manage to get our students through classes safely and at the end of the year their results normally reflect their actual strengths or weaknesses despite what is reported in those aforementioned bad reviews. While literacy and comprehension seem to have improved as the general populace (e.g. students' parents and family) will have gone through the education system, sometimes to degree level or above, behavior problems in middle schools are becoming more of an issue in recent years, with bullying and cyberbullying, hate crime, sexting, substance abuse 
and threats on the rise. As in UK schools, schools and school staff in Italy are gradually gaining more awareness as regards these concerns which once were found only in college or high school contexts - and there are several online and school-run projects and teachers' workshops which tackle such concerns (safeguarding whistleblowing and so on) and provide support for both teachers and families. Our schools no doubt could do with better safeguarding as regards rules about the 'safe' use of mobile phones in the classroom; at the moment, this is considered to be the sole responsibility of teachers who will confiscate the devices if found in use when not allowed under supervision e.g. internet searches, online dictionary or quizzes.

There is a difference to note as regards the career path to teaching and how Italian teachers are appointed insofar as achieving a career in teaching is concerned, it is important to point out that, no matter how long you might have worked on contract or supply assignments, the only way to become permanent teaching staff in Italy is by a Concorso a cattedra and abilitazione (National Examination Board) for state schools. This exam will allow people of all ages with the relevant degree titles to enter a graduatoria, meaning a list of prospective or current teachers with a specific score given to them once they pass the test. This list is publicly shown and published both online and in paper format. Effectively, because of the number of candidates, it can take up to ten years for anyone to gain a permanent post, and there is no certainty that anyone could get the desired location or school when they are called by MIUR to take their assignment. Once you become permanent your role can only vary if you apply for transfer or assignment to other schools for which you can provide MIUR with an online application. You cannot change the subject you teach however, unless you take an additional degree and 'Concorso'. Once permanent, a teacher is effectively directly responding to MIUR by way of your principal, who will variously encourage or discourage transfer applications where there is very little chance of obtaining the post you seek. (Note 15) School principals are also bound to follow the same rules and should always be on teachers' side and try and support them for the good name of the school - it is sadly a very well-known fact that as reported by the media, these days lower secondary school teachers and staff are often targeted by students and parents alike, with little or no respect for the institutional role we represent whilst in office. Is this not to be seen as a threat to our country's government? For those who took Italian history, Benito Mussolini saw fit to destitute a large number of teachers he deemed as 'anti-fascist', only to replace them with his chosen, obedient group. His nightmarish shadow seems still cast upon us, though our tangible Constitution and its articles gladly save us from our un-glorious past. (Note 16) Clearly, the immediate realization follows, history cannot repeat itself. Briefly mentioning MIUR's guidelines and addenda in this connection, I am hopeful that such literature from within the specific field of teaching in Italian schools will help other scholars and teachers in making more cross-cultural connections about education, behavior and schooling and neither stay niched in specialist study fields not simply posting on less than scientific forums and blogs or e-zines. Not much indeed, appears to have been said about teaching foreign languages and how our subject depends very much on our ability as teachers to avail ourselves of online resources and device-oriented learning tools, such as 'Edmodo' or online dictionary tools. How professional and safe are these tools, really? How formative, in this respect, are the various communities and teacher-orientation groups in relation to high-tech tools in the classroom? British Council, for instance, presents a range of online resources to use in class which provide us with safe age-related content and adds interactive options for students who choose to try out their English with language exercises from home or if in class - on a whiteboard or tablet. Many more examples are close at hand, such as the BBC educational pages e.g. Bitesize or Learning English. (Note 17) Within this context, it has become a pivotal concern for myself as EFL teacher and I believe for most colleagues in this field to stress the importance of stimulating students' awareness of how a multitude of meanings can impact any type of conversation and to enable them to use available resources so that they will begin to differentiate autonomously between varying aspects of same word or verb usage in different contexts. (Note 18) Phrases such as 'See for yourself' and 'I'll leave you to your own devices' have become very dangerous as children and especially young adults are crossing that special phase in their life where 'bridging the gap' does not happen on your own without serious consequences. In sanctioning terms, our schools do not choose, or only very rarely, to either fail, exclude or otherwise hinder our students' secondary school path as it is a well-known and recorded fact that failing teenage students in Italy often leads to them becoming involved in illegal activities and completely dropping out, or to being involved in child-labor by their families which will unfailingly blame the school for having sanctioned their 'innocent' child. Nor does Italian law allow schools to impose additional school hours, hot room time or other similar punishments considered unlawful in Italy; however, we do consider suspending students from school for a varying period of time or three days to a week usually, when their behavior becomes an obstacle to the teachers' normal work-day at school to the point of hindering or - even worse - damaging or injuring other students and sadly, of late, teachers themselves as many online reports point out. Safety in the classroom has thus become a priority nowadays as learning is inevitably to be made coterminous with the need for a safe and serene environment, for both students and teachers alike. 
Having previously mentioned inclusive policies in Italian schools, may I add that this is considered a completely normal aspect of school life, and again it would be seen as difficult, if not embarrassingly unlawful, to suggest the possibility of a return to non-inclusive settings in Italian schools. Effectively, special schools in Italy were abolished in 1977 when the role of a 'support teacher for impaired students' was created and all students were merged to form inclusive classrooms. Since 2015 an additional law was passed to make all support teachers fully recognized teachers according to our department of education and its guidelines. (Note 19) All students, impaired or not, of all social backgrounds, sex and ethnical provenance must be included - there are no special sections, schools or classes - and they must all be made to feel welcome when they come to school. This is especially true when they are entering their first year or when they have recently moved to this school from another town. Most schools in Italy have an inclusive policy which allows students with differing degrees of impairments to attend classes normally with the help of a SEN or TA professional. (Note 20) With regard to the varying contexts of inclusiveness in Italian schools, I will refer to Pamela Bianco's all-informative essay, 'I Contesti della Speciale Normalità' (2016) and its related reference literature. It is to be noted, in this connection that studies in this field are not particularly common and that there seems to be sparse evidence of specific aspects apart from what most teachers - even non-SEN or non-TAs - should know about disability ('diversamente abili' in Italian). Pamela Bianco's study therefore represents an important scholarly addition to this field. (Note 21) Considering a very real and current concern with the importance of healthy schools - and particularly - of having to avoid spreading possible illnesses, Italian schools I will briefly mention, have recently taken an important step forward in this regard by becoming more stringent thanks to a law which forbids unvaccinated children from enrolling in schools - this aspect seems less relevant when compared with the more straightforwardly scholarly concerns such as students' progress or class-structuring and teaching methods, but it is a well-known fact that some kinds of debilitating illnesses and their consequences may no doubt hinder a child's growth not simply physically but also psychologically, thus affecting their ability to learn, sometimes to disabling degrees. Parents in Italy, these days, will have to refer to a chart listing obligatory vaccinations their children must have in order to register with Primary schools. (Note 22)

\section{Conclusions}

This paper provides an excursus of some crucial aspects which characterizes 'worlds apart' - and in no way seeks to present an exhaustive outline of differences and similarities between two educational systems such as the UK and the Italian system, only to provide some examples and ideas for future research in this field, thus far somewhat lacking and often detrimental to either or both country systems. There is no question that Italian and British systems widely differ. From both, I have gained much knowledge, and I believe there is much more to learn still. The fact itself for instance, that there is very little in English translation from our array of cross-country or cross-cultural, sociological and Pan-European studies in Italian, is itself symptomatic I believe of such an unwillingness from abroad to listen to our foreign-sounding opinions, which are often considered oddities within a well-informed world ensconced in its disinterest with views held from none too distant outsiders.

Drawing comparisons, therefore, where this is at all possible, does not imply an evaluation 'for or against' one or the other system - it simply means researching the positive aspects of both systems which are still however to be thought of as separate identities. Possibly, shaking that unwillingness into considering a different approach toward the educational world. Education in this sense does not necessarily imply learnedness, but reflects on those very few steps which bring students to believe in learning and making some progress in their becoming more aware, ready to continue learning throughout their lives. What works for Italians, it is true, does not necessary work for the British. The 'new' law concerning vaccines which The BBC wrote about recently and which for reasons of space I only sparsely touched upon, is in fact considered the norm in the UK, where vaccines are given by NHS trained personnel: these can be administered within the school grounds themselves.

Conversely, in Italy, recently and for the first time, the government jointly with our health system advisors decided to pass a law in this direction; stepping past old practices in this case has meant paving the way for a better, safer and heathier future. Children today must be vaccinated in order to be accepted in Primary schools in Italy, thus reducing by much the risk of contagion between home and school grounds. This pro-vaccination law, from as early as 2013, is part of a much wider governmental program intended to disband dangerous anti-vaccination associations (Anti-vaxers) bordering on bio-terrorism, which the World Health Organization (WHO) considered 'one of the top 10 global public health threats of 2019'. Whether or not one decided to support our government and institutions, this proved to some skeptical misbelievers that if Utopia and 'ideal conditions' may not be achieved Italy can adopt new important strategies to ensure public and civil safety - while respecting people's constitutional rights to form ethical decisions and to freedom of opinions, whichever way they decide to promulgate these. (Note 23) Awareness as regards these complexities therefore is now becoming widespread and in 2019 Italy, as the situation at present for those of us who have lived abroad, may possibly compare with the general sensation of 
paranoid anxiety which permeated all strata of society in England in the early 2000s - a type of anxiety I unfortunately remember well. (Note 24)

This renewed paranoia comes partly, in 2019, as a reflection of the fact that in many countries, as people travelled less in the past, there was less of a real need for certain types of vaccines to be had. It is no longer safe today to say, 'this does not happen in my country or town'. It is, really, a matter or fighting with a Gestalt, of the idea of what a country or a cohort of countries mean singularly vis-a-vis other cross-national contexts and their practices, but which can no longer be considered individually or as separated from them. (Note 25) Italy is not shying away from itself, it is slowing picking up pace with the rest of Europe - even catching up with those Europeans who would rather not want to be part of Europe or those who are strenuously advocating an exit from Europe. This is part of the democratic process. It should not be seen as hindering it - it would be dangerous as in any political realm, not to acknowledge what the people wish from their governments. It is also a very delicate matter involving Europe and - in fact - all other allied countries. The more fragmented international relationships become, the more dangerous and frail our safety in the wake of recent threats posed to many of our countries. Stepping past Europe would mean for Italians these days, to step past or beyond Italy - are we sure it would be safer for us to out-do ourselves and try to rewrite our Gestalt and re-think our culture? Should we not focus rather on transferring this culture and language onto our children, therefore allowing it to stay alive? How can we provide our children with a culture and/or language which does not belong to us? This perception represents the ultimate challenge for teachers, parents and all those involved in the educational process.

I will therefore close this paper with more questions: 'Who will listen to my whispers?' A similar discourse can be used to argue for or against changes to be made to our schooling system and other institutional aspects of our society. Teachers in Italy will invariably refer to a Union when they feel that their rights are being violated, and yes, we do feel strongly about less than knowledgeable comments about our government its laws and its institutional practices - we believe that whoever wishes to have a career and live in Italy should familiarize themselves with Italian language, culture and first and foremost with Italian laws.

Italy is a welcoming country as many note, however it is not neutral or indifferent as regards crucially misinformed comments about how things are done in our country or indeed, in Europe. Our fondness for our constitutional rights reflects this stance, as well as our pride in rights of workers, freedom of speech and communication in all its forms, the arts and crafts, and any other lawful means of divulging opinions and ideas. In the classroom, a teacher's autonomy begins with how we devise our own classes and goes on with trying out new approaches and methods every time. It is no hyperbole to remark that none but fools dare to comment on how a teachers' class was taught - as work is considered sacred and it should be respected, if it does not cause problems for others - we are rather expected to provide inspired and considerate feedback, which is a different aspect of our job, but only when asked formally to do so, for example on how a class-group performed on an interdisciplinary project, or during a visit to museums on school trips.

The sad feeling however, is that such pride is not respected, and nowadays deluded parents deem it possible to 'oust teachers out' on the grounds that 'they do not like them'. The law here does come and help us somewhat, and in the same way that it is not possible to hire a mafia boss to get rid of your enemy, it is not possible in Italy to pay someone off to get rid of a teacher...or is it? Very worryingly, I am hoping for better times ahead. I do believe we are all on the same side - and trust in our countries' authorities. It's not strictly speaking the same thing as believing in Santa Claus after all, and if this is an example of Gestalt, a 'system of systems', I hope it works. It is not by chance, I am afraid to say, that changes to the Constitution of the Italian Republic was attempted not long ago, and failed. (Note 26) Same goes for changing definitions: students, children, minors: how do words and labels affect identity and social conditions? How do we define a problem child? Is it ethical to conceive of a child as 'problematic'? Or are we, rather, the problem? Well, in the eyes of the law that problem disappears - to be more specific, it cannot be considered as being lawfully 'problematic'. Therefore, where there is no problem, there is nothing to solve.

Our new children - are they welcome? Do they feel welcome enough? Do we, as we must, make them feel safe when they are at school? Educational practices in Italy and abroad are knowledge-providers who carry out outstanding work as part of a pre-imposed ethical obligation, often free of charge, or for less than they should be remunerated; we are politically aware and correct and would not ask for a 'like' on our school social profile; indeed, as already previously mentioned, social networking etiquette remains to this day an important aspect gearing students to use their 'cyber-world' correctly and safely stays a primary aspect of our fight against cyber-crime and other related dangers.

The question was often posed to me, among many more, how acceptable is it for teachers to be present on social networks? This article I believe provides some possible answers; from an educational point of view, my opinion as a teacher is that it should now be made a requirement for teachers to 'be out there' as being on social media 
sometimes represents the only port of communication between teachers and co-workers - and at schools, it can be used for emergencies too. Certainly, this does not automatically mean teachers must add their students to their network. (Note 27)

\section{Suggestions}

To conclude this brief excursus, asking questions is always the best way of finding out what others know already; thus, this paper closes with more questions than it started out with: 'What do you learn from a government-run education?' 'Where do you learn respect for people and ethics' 'What are the confines of an increasing cross-linguistic and cross-cultural merging in Italy? 'How do we tackle similar problems in our schools?' and finally, self-reflectively, 'What does MIUR say about such questions?' This paper does in fact mention some research recently carried out by MIUR (Ministero della Pubblica Istruzione e della Ricerca); most of it however, is available, for the time being, only in Italian - exception made for instance for 'English corner' (Matera European Capital of Culture 2019) recently published by MIUR in their pages. (Note 28) To add to reference material already quoted in this paper, I could point scholars willing to take further challenge to such informed and well-read journals as the Italian Journal of Educational Research or The Italian Journal of Sociology of Education - these are still very much 'niche' review journals meant for educational specialists.

I would rather suggest that what would be required in this context is some more pioneering translation work of extant research into English, meant to present our teaching colleagues and work-peers overseas with what our Education agency (MIUR) deems necessary in terms of our educational policies, in order to foster a perception of the Italian educational system as non-stereotypical, internationally valid and worthy of considered mention abroad; wishing to push past the language barrier apparently posed by Italian as a language or 'cross the language wall' nowadays does mean translating some of that research into English. (Note 29) In the light of what Europe and Italy within Europe is experiencing politically today, being able to glean new educational or governing trends will be leading in the future will no doubt depend on which abilities and communicative modalities will be employed in order to 'cross that cultural border'. It would be interesting, certainly, to ascertain the level of awareness as regards up-to-date concerns in schools and widely within the education field as raised by similar research and by this paper - as well as proposing other possible Pan-European and/or non-European parallel readings of such work presented by scholars in this field.

\section{References}

Bianco, P. (2016). I contesti della speciale normalità. Integrazione vs inclusione; pedagogia vs didattica, EDSCUOLA. https://www.isisvarese.edu.it/wp-content/uploads/2015/11/QUADRO-NORMATIVO-DELLINTEGRAZIO NE-SCOLASTICA.pdf'; What is a Gestalt' pdf article http://www.gisc.org/gestaltreview/documents/WhatsaGestalt.pdf

Dron, J., \& Anderson, T. (2014). Teaching Crowds. Learning and social media. AU Press Athabasca University. Retrieved from https://teachingcrowds.ca/discuss-the-chapters/chapter-9-issues-and-challenges-in-educational-uses-of-socia 1-software

Griffiths, P. [2006] (2017). An Introduction to English Semantics and Pragmatics (2nd ed.). Edinburgh University Press. See chapters 1, 5, 7, 9.

'I quaderni di Eurydice'. Retrieved 22 August 2019, from https://eacea.ec.europa.eu/national-policies/eurydice/sites/eurydice/files/the_structure_of_the_european_ed ucation_systems_2018_19.pdf

'Il Manifesto di Ventotene" [http://www.ossimoro.it/ventotene.html]. A rare filmed documentary by 'Istituto Luce' about schools in Italy during Fascism presented in English. Retrieved 24 August 2019, from https://www.youtube.com/watch?v=qaDsHpwEAO8

Iniobong, F. A., \& Atim, E. I. (2019, August). Students' Perception of Lecturers' Utilization of Information and Communication Technology (ICT) Tools for Instructional Delivery in Science Education Programme. Journal of Education and Development, 3(2).

$\begin{array}{lllll}\text { Italian Law } & \text { L17. (1977). } & \text { Retrieved }\end{array}$ https://www.tecnicadellascuola.it/compie-40-anni-la-legge-517-sull-integrazionehttp://www.museotorino.it/ view/s/eda5a4a4b3bc4488ac992cf9adb45a76; cf

Partridge, C., \& Spoth, J. (2013). Deepening awareness. A Gestalt approach to coaching. Coaching Today, April issue, p. $7 \mathrm{ff}$. 
Pier Luigi Dini. (1966). Classi differenziali e scuole speciali: ordinamento italiano e cenni di legislazione comparata, Armando, Roma.

\section{Notes}

Note

https://ww.educazioneglobale.com/2017/12/the-italian-education-system-explained-to-english-speaking-expats/; https://www.italymagazine.com/featured-story/back-school-10-things-you-should-know-about-italian-school-sys tem [24 August 2019]

Note

https://www.understandingitaly.com/education.html; https://www.lifeinitaly.com/moving/school-system-in-italy [24 August 2019]

Note 3. Partridge C., Spoth, J, (2013). "Deepening awareness. A Gestalt approach to coaching". In Coaching Today (April issue, p. $7 \mathrm{ff}$ ).

Note $\quad 4 . \quad$ https://miur.gov.it/unione-europea

https://miur.gov.it/web/guest/sistema-educativo-di-istruzione-e-formazione

http://archivio.comune.pv.it/museicivici/pdf/annali29/91\%20Rognoni.pdf; though I would be quite glad to translate these articles in English, there is little time to devote to this complex task. Cf. 'Il Manifesto di Ventotene" [http://www.ossimoro.it/ventotene.html].

Note 5.4 'I quaderni di link [https://eacea.ec.europa.eu/national-policies/eurydice/sites/eurydice/files/the_structure_of_the_european_educati on_systems_2018_19.pdf] accessed on 22-Aug-19 5:39 PM; European Union archives and link https://www.eui.eu/Research/HistoricalArchivesOfEU [accessed on 31-Aug-2019]

Note 6. Dron J, Anderson, T. (2014) Teaching Crowds. Learning and social media. AU Press Athabasca University and link: https://teachingcrowds.ca/discuss-the-chapters/chapter-9-issues-and-challenges-in-educational-uses-of-social-sof tware; see also Iniobong Fred Akpan, Atim Edet Itighise (August, 2019) Students' Perception of Lecturers' Utilization of Information and Communication Technology (ICT) Tools for Instructional Delivery in Science Education Programme in Journal of Education and Development; Vol. 3, No. 2; July Press.

http://journal.julypress.com/index.php/jed/article/view/606/454

Note $7 . \quad$ https://en.m.wikipedia.org/wiki/Young_offender; https://www.t2a.org.uk/wp-content/uploads/2011/09/T2A-International-Norms-and-Practices.pdf

Note

https://www.europol.europa.eu/crime-areas-and-trends/crime-areas/mafia-structured-crime-areas-and-trends-gro ups-ocg [accessed 31-Aug-2019]

Note 9. http://luosimagazine.blogspot.com/2015/02/differences-between-english-and-italian.html [23 August 2019]

Note

https://www.educazioneglobale.com/2017/12/the-italian-education-system-explained-to-english-speaking-expats / [24 August 2019]

Note 11. My UK teaching experience refers to 2014-2017. I resumed teaching in Italy full-time in 2017.

Note 12. A rare filmed documentary by 'Istituto Luce' about schools in Italy during Fascism presented in English. https://www.youtube.com/watch?v=qaDsHpwEAO8 [24 August 2019]

Note

https://studioallestero.wordpress.com/2015/12/26/che-differenza-ce-tra-la-scuola-nel-regno-unito-e-quella-italian a/ ; https://www.amichedifuso.com/2017/05/29/differenze-fra-scuola-inglese-italiana-didattica-istruzione/

Note $14 . \quad$ https://www.studenti.it/sistema-scolastico-in-gran-bretagna.html; https://www.scribd.com/doc/311289834/hyperbole-lesson-plan

https://study.com/academy/lesson/methods-of-teaching-hyperbole.html;

Note 15. https://education.stateuniversity.com/pages/722/Italy-TEACHING-PROFESSION.html [23 August 2019]

Note 16. http://www.italianinsider.it/?q=node/6654 ; http://www.italianinsider.it/?q=node/7353. https://www.simonescuola.it/docente/5_1.htm 
Note $17 . \quad$ British Council [https://learnenglishteens.britishcouncil.org/] $\quad$ BBC [https://www.bbc.co.uk/search?q=bitesize ; http://www.bbc.co.uk/learningenglish/] 22-Aug-19 7:00 PM; ; http://www.indire.it/lucabas/lkmw_img/eurydice/quaderno_eurydice_30_per_web.pdf 22-Aug-19 8:42 PM;

Note 18. Griffiths P., [2006] (2017). An Introduction to English Semantics and Pragmatics, 2nd ed., Edinburgh University Press. See chapters 1, 5, 7, 9.

Note $19 . \quad$ Italian $\quad$ Law $\quad 517 \quad$ (1977) link https://www.tecnicadellascuola.it/compie-40-anni-la-legge-517-sull-integrazionehttp://www.museotorino.it/view /s/eda5a4a4b3bc4488ac992cf9adb45a76; cf. Pier Luigi Dini, (1966) Classi differenziali e scuole speciali: ordinamento italiano e cenni di legislazione comparata, Armando, Roma.

Note 20. Acronyms such as SEN teacher (Special Educational Needs) and TA (Teaching assistants) are coterminous with the phrases 'insegnante di sostegno' or 'docente di sostegno'. The acronym 'SEN/D' children is coterminous with 'studenti DSA (disturb specific dell'apprendimento) or student BES (bisogni educative speciali)'. In this connection as specifically related to language learning disabilities, cf. 'I bisogni linguistici specifici. Daloiso, M. (2016) (ed.) Inquadramento teorico, intervento clinic e didattica delle lingue', Erickson.

Note 21. Bianco, P. (2016), I contesti della speciale normalità. Integrazione vs inclusione; pedagogia vs didattica, EDSCUOLA.

https://www.isisvarese.edu.it/wp-content/uploads/2015/11/QUADRO-NORMATIVO-DELLINTEGRAZIONE-S COLASTICA.pdf

Note $22 . \quad$ https://www.bbc.com/news/world-europe-47536981; https://www.vaccinestoday.eu/stories/vaccines-mandatory-italy/;

https://gizmodo.com/italy-begins-to-enforce-no-vaccines-no-school-policy-a-1833249972

Note

http://www.salute.gov.it/portale/vaccinazioni/dettaglioContenutiVaccinazioni.jsp?lingua=italiano\&id=4826\&area $=$ vaccinazioni\&menu $=$ vuoto

Note 24. https://www.ncbi.nlm.nih.gov/pmc/articles/PMC5198166/

Note 25. Cf. 'What is a Gestalt' and pdf article http://www.gisc.org/gestaltreview/documents/WhatsaGestalt.pdf

Note

http://espresso.repubblica.it/palazzo/2016/01/13/news/come-funziona-il-referendum-costituzionale-che-potrebbe -mandare-a-casa-il-governo-renzi-1.246523; Senato ed approvazione delle variazioni alla legge elettorale https://senato.it/Leg17/3381?comunicato=54257\# - governo e Buona Scuola (2017).

Note

https://www.europol.europa.eu/activities-services/public-awareness-and-prevention-guides/cyber-crime-vs-cyber -security-what-will-you-choose (31-Aug-2019)

Note 28. Matera European Capital of Culture 2019 - https://miur.gov.it/english-corner ; https://rio.jrc.ec.europa.eu/en/organisations/ministry-education-university-and-research-miur

Note $29 . \quad$ https://ojs.pensamultimedia.it/index.php/sird/index; http://www.oecd.org/education/Education-Policy-Outlook-Country-Profile-Italy.pdf;

http://ijse.padovauniversitypress.it/issue/11/3

\section{Copyrights}

Copyright for this article is retained by the author(s), with first publication rights granted to the journal.

This is an open-access article distributed under the terms and conditions of the Creative Commons Attribution license (http://creativecommons.org/licenses/by/4.0/). 